\title{
Diversidade cultural e religiosa: o ensino religioso e as religiões de matrizes africanas na educação escolar
}

\section{Cultural and Religious Diversity: religious education and the religions of the African} matrices in school education

Elivaldo Serrão Custódio*

\begin{abstract}
Resumo
O presente artigo objetiva refletir sobre a diversidade cultural e religiosa na educação escolar enquanto desafio para uma educação inclusiva. A educação escolar, vista pelo viés da diversidade cultural, torna-se um desafio na atualidade brasileira, pois ela será obrigada a fazer o exercício de rever os seus caminhos, refletindo como ensina e o que ensina. O presente trabalho trata do resultado de um estudo exploratório de natureza qualitativa que adotou a pesquisa bibliográfica, a análise documental e a entrevista como forma de investigação. Os resultados apontam que na literatura contemporânea as Religiões de Matrizes Africanas (RMA) encontram-se instaladas no espaço brasileiro, apresentando-se como religiões estruturalmente organizadas, com crenças e ritos, portanto, possuidoras de fenômenos religiosos. Acreditamos que sem a valorização e o respeito às RMA na disciplina de Ensino Religioso (ER) e no Ensino da Cultura e História da África e dos Afro-Brasileiros não prevalecerá o dispositivo legal na preservação e valorização da cultura. O Brasil é um país rico na sua diversidade cultural e religiosa. É de responsabilidade do Estado a elaboração de diretrizes para definição de uma política pública voltada para a educação na perspectiva da diversidade, assim como uma política educacional voltada para a proteção das RMA como patrimônio cultural.
\end{abstract}

\section{Palavras-chave}

Diversidade cultural e religiosa. Ensino Religioso. Religiões de matrizes africanas. Educação escolar. Amapá.

[Texto recebido em janeiro de 2017 e aceito em junho de 2017, com base na avaliação cega por pares realizada por pareceristas ad hoc]

Uma versão preliminar deste artigo foi apresentada no GT-6: Religião e Educação do $28^{\circ}$ Congresso Internacional da Sociedade de Teologia e Ciências da Religião (SOTER), que ocorreu em Belo HorizonteMG, na PUCMinas, no período de 14 a 17 de julho de 2015, com a temática Religião e espaço público: cenários contemporâneos.

* Mestre em Direito Ambiental e Políticas Públicas (UNIFAP). Doutorando em Teologia (Escola Superior de Teologia). Brasil. Bolsista da CAPES. Docente da Secretaria de Estado de Educação do Amapá (SEED). Membro Pesquisador do Grupo de Pesquisa Centro de Estudos Políticos, Religião e Sociedade (CEPRESUNIFAP/CNPq), do Grupo de Pesquisa Educação, Relações Étnico-Raciais e Interculturais (UNIFAP/CNPq), do Grupo de Pesquisa Currículo, Identidade Religiosa e Práxis Educativa e do Grupo de Pesquisa Identidade (Faculdades EST/CNPq). E-mail: elivaldo.pa@hotmail.com 


\begin{abstract}
This article aims to reflect on cultural and religious diversity in school education as a challenge for inclusive education. School education, view the perspective of cultural diversity, it becomes a challenge in Brazil today as it will be required to do the exercise to revise their ways, reflecting how and teaches what it teaches. This work deals with the results of an exploratory qualitative study which adopted the literature review, document analysis and interviews as a way to research. The results show that in contemporary literature the African headquarters of Religions (RMA) are installed in the Brazilian space, appearing as structurally organized religion, with beliefs and rites, therefore, possessed of religious phenomena. We believe that without the appreciation and respect for RMA in Religious Education discipline (ER) and in the Education of Culture and African History and Afro-Brazilian will not prevail the legal provision in the preservation and enhancement of culture. Brazil is a country rich in its cultural and religious diversity. The State has the responsibility of drawing up guidelines for defining a public policy aimed at education from the perspective of diversity, as well as a focused educational policy for the protection of the RMA as cultural heritage.
\end{abstract}

\title{
Keywords
}

Cultural and religious diversity. Religious Education. Religions of African origin. School education. Amapá.

\section{Introdução}

O Brasil é um país que se constitui em meio à diversidade. Isso significa dizer que a temática da diversidade e da diferença não é um problema inédito nos estudos na área da Educação, de modo que não podemos ignorar as importantes contribuições e teorizações que foram construídas a esse respeito.

Contudo, discutir diversidade cultural implica nos posicionarmos contra os processos de dominação, pois observamos que a democracia que assegure a igualdade efetivamente e a cidadania política apresentam-se como a grande contradição do capitalismo contemporâneo. Cabe lembrarmos que a noção de cidadania nos dias atuais tem ocupado espaços nas justificativas de ações de promoção da desigualdade social.

A cultura adquire formas diversas por meio do tempo e do espaço, que por sua vez, manifestam-se na originalidade e na pluralidade das identidades que caracterizam os grupos e a sociedade que compõem a humanidade. Sendo fonte de intercâmbio, inovação e criatividade, o meio ambiente cultural bem como a diversidade cultural é, para o gênero humano, tão necessário quanto a diversidade biológica para os organismos vivos.

Diante dessa perspectiva, a educação escolar, vista pelo viés da diversidade cultural, torna-se um desafio na atualidade brasileira, pois ela será obrigada a fazer o exercício de rever os seus caminhos refletindo como ensina, e o que ensina. E nessa 
trajetória, cabe, pois, à escola, o papel central no processo de construção da realidade social.

É importante observarmos que o conceito de patrimônio cultural não se restringe à produção material humana, mas abrange também a produção emocional e intelectual, ou seja, tudo o que permite ao homem conhecer a si mesmo e ao mundo que o rodeia pode ser chamado de bem cultural. ${ }^{1} \mathrm{Na}$ legislação brasileira, a questão sobre a diversidade cultural pode ser encontrada nos Temas Transversais dos Parâmetros Curriculares Nacionais (PCN), que vem tratando em diferentes momentos sobre Pluralidade Cultural e Ética. ${ }^{2}$ Logo, é pertinente afirmarmos que a valorização do patrimônio cultural brasileiro passa pela ação pedagógica com o objetivo de desenvolver o processo permanente e sistemático de inserção do conhecimento junto à comunidade.

Cabe também lembrarmos que falar de diversidade cultural e currículo escolar é um grande desafio para os profissionais da educação da atualidade, pois nos remete para uma discussão de processos de implementação curriculares com a participação efetiva de todos os envolvidos no sistema de ensino, principalmente pelos profissionais de diferentes níveis e modalidades de ensino de forma integrada. Todavia, esta participação em massa, tem sido a grande dificuldade enfrentada no momento de elaboração e/ou organização curricular.

Falar de currículo escolar envolve ainda uma discussão sobre como as políticas curriculares são políticas de conhecimento, uma vez que na maioria das vezes a seleção do que deve ou não ser contemplado não é neutra. Mesmo aquelas disciplinas que são apontados pela Lei n. 10.639/2003, cujo programa deve constar conhecimentos relativos à História e Cultura Afro-Brasileira e Africana, o tratamento a esses conteúdos é silenciado ou não é tratado de forma devida. ${ }^{3}$

O presente trabalho é resultado de um estudo exploratório de natureza qualitativa que adotou a pesquisa bibliográfica, a análise documental e a entrevista como forma de investigação. O texto é parte na Dissertação de Mestrado apresentada no ano de 2014 ao Programa de Pós-Graduação em Direito Ambiental e Políticas Públicas da Universidade Federal do Amapá (UNIFAP). ${ }^{4}$ Assim sendo, o presente trabalho esboçará a educação em diversidade, abordando a religiosidade africana como patrimônio cultural imaterial e, por

SILVA, Kalina V.; SILVA, Maciel H. Dicionário de conceitos históricos. 2. ed. São Paulo: Contexto, 2006.

2 BRASIL. Ministério da Educação. Parâmetros Curriculares Nacionais: pluralidade cultural e orientação sexual. Brasília: SEF/MEC, 1998b.

3 BRASIL. Lei $n$. 10.639, de 09 de janeiro de 2003: instituiu a obrigatoriedade do ensino de História e Cultura Afro-Brasileira e Africana no Currículo da Educação Básica. Disponível em: <http:/ / www.planalto.gov.br/ccivil03/Leis/2003/L10.639.htm>. Acesso em: 01 out. 2011.

4 CUSTÓDIO, Elivaldo S. Políticas públicas e direito ambiental cultural: as religiões de matrizes africanas no currículo escolar no Amapá. Dissertação (Mestrado em Direito Ambiental e Políticas Públicas) Universidade Federal do Amapá, Macapá, 2014. 198f. 
fim, o currículo, a diversidade cultural, as relações étnico-raciais e o ensino religioso no espaço escolar: desafios e perspectivas.

\section{Educação em diversidade: a religiosidade africana como patrimônio cultural imaterial}

A questão do reconhecimento das Religiões de Matrizes Africanas (RMA) como patrimônio cultural imaterial da humanidade não é uma discussão recente. $O$ não reconhecimento da religião dos negros, a intolerância religiosa com relação às religiões de herança africana, e a crítica/negação delas em oposição à matriz judaico-cristã, vêm dificultando a construção de uma cultura de respeito à diversidade.

Do ponto de vista cultural, a diversidade pode ser entendida como uma "construção histórica, cultural e social das diferenças, ultrapassando as características biológicas, observáveis a olho nu". 5 A urgência em trabalharmos com a diversidade, atualmente implica pensar a maneira como a escola lida com essa questão no seu cotidiano, no seu currículo, nas suas práticas. A diversidade cultural não pode ser desvencilhada também da noção de diversidade da vida.

Segundo Celso Antônio Pacheco Fiorillo, um dos primeiros conceitos de patrimônio cultural foi trazido pelo Art. $1^{\mathrm{o}}$ do Decreto-Lei n. 25/1937, que determinava constituir patrimônio histórico e artístico nacional o conjunto dos bens móveis e imóveis existentes no país. ${ }^{6}$ Todavia, a Constituição Federal (CF) de 1988 trouxe em seu Art. 216 o conceito de patrimônio cultural, a saber:

[...] Art. 216 - Constituem patrimônio cultural brasileiro os bens de natureza material e imaterial, tomados individualmente ou em conjunto, portadores de referência à identidade, à ação, à memória dos diferentes grupos formadores da sociedade brasileira nos quais se incluem: I - as formas de expressão; II - os modos de criar, fazer e viver; [...].7

Ao analisarmos o caput do Art. 216, percebemos um avanço significativo em relação ao tratamento do bem cultural, pois na formulação de seu conceito, o aspecto imaterial absorveu os mais variados e modernos significados de imaterialidade.

Sabemos que desde sua criação em 1945, a Organização das Nações Unidas para a Educação, a Ciência e a Cultura (UNESCO) tem assumido uma tarefa árdua na luta e defesa da população mundial por melhores condições de vida. Por isso, a Convenção para

5 GOMES, Nilma L. Indagações sobre currículo: diversidade e currículo. Brasília: Ministério da Educação, Secretaria de Educação Básica, 2008. p. 17.

6 FIORILlO, Celso A. P. Curso de direito ambiental brasileiro. 13. ed. rev. atual. e ampl. São Paulo: Saraiva, 2012.

7 BRASIL. Constituição Federal. Brasília, $1988 . \quad$ Disponível em: <http://www.senado.gov.br/sf/legislacao/const/con1988/CON1988_30.06.2004/CON1988.pdf>.

Acesso em: 28 ago. 2011. 
a Salvaguarda do Patrimônio Imaterial criada em $2003^{8}$ dedicou-se exclusivamente à problemática que envolvia o patrimônio cultural imaterial, destacando já no Art. $2^{\circ}$ do seu documento, dizendo que o patrimônio imaterial ou intangível seria afirmado como:

[...] Práticas, representações, expressões, conhecimentos e técnicas - junto com os instrumentos, objetos, artefatos e lugares culturais que lhes são associados - que as comunidades, os grupos e, em alguns casos, os indivíduos reconhecem como parte integrante de seu patrimônio cultural. ${ }^{9}$

É importante observarmos que o patrimônio cultural imaterial é contemplado no primeiro e em parte do terceiro inciso do Art. 216 da CF de 1988. Expressa José Eduardo Ramos Rodrigues que se trata de um patrimônio em geral intangível, não tridimensional, mas científico, de conhecimentos, de tecnologia, de todas as disciplinas, erudita e popular. A cultura não é algo dado como uma simples herança que se possa transmitir de geração a geração. Ela é uma produção histórica, como parte das relações entre os grupos sociais. ${ }^{10}$

É nesse plano social que Sandra de Cássia Araújo Pelegrini e Pedro Paulo Abreu Funari afirmam que o patrimônio, antes restrito ao excepcional, aproximou-se, cada vez mais, das ações quotidianas, em sua imensa e riquíssima heterogeneidade. Nossos autores destacam que essa forma de pensar se expandiu com a intensificação dos trabalhos da UNESCO, ampliando-se não somente aos monumentos suntuosos representativos do ponto de vista dos poderes hegemônicos, mas também as construções mais simples e integradas ao dia a dia das populações e mais recentemente os bens culturais de natureza intangível como, por exemplo, expressões, conhecimentos, práticas e técnicas populares, as comidas, os saberes, fazeres e falares. Com base nesses fatos, entre outros, podemos afirmar que as RMA estão intrinsecamente ligadas e incluídas como patrimônio ambiental cultural da humanidade. ${ }^{11}$

As religiões estão presentes na vida do ser humano ao longo de sua história e todas elas são parte importante da memória cultural e do desenvolvimento histórico de toda sociedade. Neste sentido, a religião desempenha ou pode desempenhar um papel importante na sociedade.

Em se tratando de religião ${ }^{12}$ em nosso país, ao observarmos os dados estatísticos apresentados pelo último Censo do IBGE em 2010,13 podemos afirmar que o brasileiro se

8 ORGANIZAÇÃO DAS NAÇÕES UNIDAS PARA A EDUCAÇÃO, A CIÊNCIA E A CULTURA (UNESCO). Convenção relativa à luta contra a discriminação no campo do ensino. Paris: UNESCO, 2003.

9 PELEGRINI, Sandra de C. A.; FUNARI, Pedro P. A. O que é patrimônio cultural imaterial. São Paulo: Brasiliense, 2008. p. 46.

10 RODRIGUES, José E. R. Patrimônio cultural: aspectos polêmicos. Revista de Direito Ambiental, São Paulo, ano 6, n. 21, jan./mar. 2001.

11 PELEGRINI; FUNARI, 2008.

12 Não temos a intenção de fazer uma longa discussão sobre o conceito de religião neste trabalho. Entretanto, destacamos o pensamento de M. Eliade, quando expressa que religião é um sistema infinitamente complexo, que pode ser apontado como uma referência primordial. Conforme o autor, a 
autodeclara religioso ${ }^{14}$ e que essa religiosidade é muito particular de cada um. Entretanto, na prática devocional, uma boa parte dessa população não é praticante de nenhuma religião.

Isso demonstra que a questão religiosa no Brasil é muito complexa, devido à sociedade ter à sua disposição uma fantástica multiplicidade de crenças e práticas religiosas. E esta diversidade de modos de organização está na base da formação histórica, marcada e modelada por uma pluralidade de registros e de códigos: de civilizações, de economias, de religiões, de personagens, de paisagens, etc.

Sobre a participação dos africanos na construção do Brasil, José Barbosa da Silva Filho declara que os africanos e seus descendentes,

[...] Foram agentes históricos que ajudaram a construir o Brasil, não só com a força de seus braços, mas principalmente, com sua inteligência, sensibilidade e capacidade de luta e articulação. Os africanos deixaram fortes influências na religião, na história, nas tradições, no modo de ver o mundo e de agir perante ele, nas formas das artes, nas técnicas de trabalho, fabricação de objetos, nos modo de falar, de vestir, na medicina caseira e em muitos outros aspectos socioculturais da nossa sociedade. ${ }^{15}$

Por ocasião das comemorações dos 500 anos do Brasil, Léa Freitas Perez declarou dizendo que a religiosidade brasileira trata-se, portanto, de um universo caracterizado por uma pluralidade de vozes, de paisagens e de formas de organização que compõe estruturalmente a sociedade brasileira. ${ }^{16}$ Neste sentido, podemos dizer que a religiosidade é um fenômeno inerente a todo ser humano e está presente em todas as culturas, manifestando-se na vida do homem ao longo de sua história.

Para Elias Wolff, religião e sociedade são realidades que se interpenetram, pois a religião concorre de algum modo para a formação na medida em que favorece a convivência dos cidadãos. Apresenta-se como um empreendimento humano que está sempre se configurando culturalmente, ou seja, existe uma estreita ligação entre cultura e

religião é o sistema de mundo das sociedades tradicionais, ao mesmo tempo, autônoma em relação à sociedade. ELIADE, Mircea. O sagrado e o profano: a essência das religiões. São Paulo: Martins Fontes, 2001.

13 INSTITUTO BRASILEIRO DE GEOGRAFIA E ESTATÍSTICA (IBGE). Censo Demográfico 2010. Disponível em:

<ftp:/ ftp.ibge.gov.br/Censos/Censo_Demografico_2010/Caracteristicas_Gerais_Religiao_Deficiencia/t ab1_4.pdf>. Acesso em: Acesso em: 30 jun. 2012.

14 Embora o Censo de 2010 tenha registrado um aumento entre a população que se declarou sem religião, pois em 2000 eram quase 12,5 milhões (7,3\%), ultrapassando os 15 milhões em 2010 (8,0\%). O Censo demonstrou ainda que $92 \%$ da população brasileira declaram-se adeptos a algum tipo de religião. IBGE, Censo 2010.

15 SILVA FILHO, José B. da. Apontamentos sobre a história do negro no Brasil. Cuiabá, EDUFMT, 2009 . p. 6.

16 PEREZ, Léa F. Breves notas e reflexões sobre a religiosidade brasileira. Edição Especial, Brasil 500 anos, junho de 2000. Belo Horizonte: Imprensa Oficial dos Poderes do Estado, 2000. p. 40-58. Disponível em: <http://antropologia.org.br/arti/colab/a8-lfreitas.pdf>. Acesso em: 15 nov. 2011. 
religião. Ambas relacionam-se intimamente, no sentido de que os princípios socioculturais interagem com os religiosos na orientação da existência humana. ${ }^{17}$

O quadro das religiões negras, ou religiões afro-brasileiras, é bastante diversificado. Reginaldo Prandi nos relata que em seu conjunto, até os anos de 1930, as religiões negras poderiam ser incluídas na categoria das religiões étnicas ou de preservação de patrimônios culturais dos antigos escravos negros e seus descendentes, enfim, religiões que mantinham vivas tradições de origem africana. Formaram-se em diferentes áreas do Brasil, com diferentes ritos e nomes locais derivados de tradições africanas diversas. ${ }^{18}$

Já na introdução da I Conferência Nacional de Promoção da Igualdade Racial (CONAPIR) ocorrida no ano de 2005 em Brasília-DF, o documento apresenta a sua visão sobre a orientação política sobre as referidas religiões afro-brasileiras:

O Estado brasileiro não pode desconsiderar o papel histórico e a contribuição que as religiões de matriz africana tiveram na formação da identidade e costumes do povo brasileiro, proporcionados pela chegada de milhares de africanos escravizados trazidos ao país. Essa população que, no confronto com o padrão dominante aqui existente, introduz e reproduz os valores e saberes da visão de mundo africana, reelaborando e sintetizando no Brasil a relação do homem com o sagrado [...].19

Observamos no decorrer da história do Brasil que a formação da antiga sociedade colonial foi realizada num território irrigado por muitos confrontos. A sociedade brasileira não surgiu, portanto, da união harmoniosa das três raças - branca, indígena e negra -, mas sim mediante a dominação da primeira sobre as demais.

Assim, a cultura africana foi invisibilizada por muitos anos, apesar de milenar e de ter construído ao longo da história, centenárias instituições que, além de serem marcos de importantes acontecimentos, foram e são elementos indispensáveis para a existência do Brasil como nação. Uma preocupação marcante da I CONAPIR refere-se ao reconhecimento das religiões afrodescendentes como "patrimônio imaterial, cultural e religioso brasileiro", enfatizando a sua contribuição para a formação da identidade racial.

Nesse contexto, precisamos, portanto, reconhecer enquanto patrimônio material e imaterial nacional, os terreiros, os babalorixás, os yalorixas, os sacerdotes e sacerdotisas

17 WOLFF, Elias. Humanismo e Religião. In: WOLFF, Elias; BENTO, Fábio Régio. Cristianismo, humanismo e democracia. São Paulo: Paulus, 2005. p. 219.

18 PRANDI, Reginaldo. As religiões negras do Brasil: para uma sociologia dos cultos afro-brasileiros. Revista USP, São Paulo, v. 28, p. 64-83, dez./fev. 1995/1996. Disponível em: <http://www.usp.br/revistausp/28/05-prandi.pdf>. Acesso em: 18 jul. 2012.

19 CONFERÊNCIA NACIONAL DE PROMOÇÃO DA IGUALDADE RACIAL. Estado e sociedade promovendo a igualdade racial (CONAPIR): relatório final. Brasília: Secretaria Especial de Política de Promoção da Igualdade Racial/Conselho Nacional de Promoção da Igualdade Racial, 2005. p. 105. Disponível em: <www.planalto.gov.br/seppir/publicacoes/relatorio_final_conapir.pdf>. Acesso em: 14 jan. 2012. 
como perpetuadores das RMA, garantir o reconhecimento legal dos terreiros como meio de promoção da cultura, educação e saúde, bem como fortalecer ações já desenvolvidas no âmbito nacional e seu reconhecimento como de utilidade pública.

A religiosidade é tão antiga quanto o ser humano. E talvez no espaço brasileiro "[...] a diversidade religiosa seja o aspecto mais significativo e que, por isso mesmo, tem merecido atenção, quando tratamos do patrimônio cultural imaterial". ${ }^{20}$ Para nossos autores, a religiosidade é um termo amplo que procura ultrapassar as definições mais estreitas de religião, crença, magia, culto, ritual ou outros, que estarão abrangidos pelo sentimento difuso associado às práticas religiosas. E esta imaterialidade dos sentimentos religiosos associa-os, de forma muito direta, ao patrimônio cultural imaterial ou intangível.

Sendo assim, do ponto de vista da cultura, a religiosidade pode ser considerada um conjunto de atividades que se articulam com as crenças e os rituais e que o patrimônio cultural imaterial religioso deve ser capaz de expressar a diversidade de interesses sociais em jogo.

As práticas de preservação e re-elaboração do patrimônio cultural imaterial afrobrasileiro, em especial, devem ser levadas em consideração, mesmo porque essas maneiras de ser, crer, fazer, viver e conhecer, chamadas de ethos de um povo ou grupo social, fundadas em uma cosmovisão africana, traduziram-se em um conjunto de saberes que puderam ser preservados e reelaborados nessas comunidades. Muito do que somos e sabemos devemos ao aporte cultural africano.

É tarefa importante o favorecimento da percepção da riqueza e do valor de um mundo plural e diversificado. As religiões não são apenas genuinamente diferentes, mas também autenticamente preciosas. Portanto, devemos honrar essa alteridade ${ }^{21}$ em sua especificidade peculiar, reconhecendo o valor da plausibilidade de um pluralismo religioso de direito ou de princípio.

\section{Currículo, diversidade cultural, relações étnico-raciais e ensino religioso na educação escolar: desafios e perspectivas}

Entendemos que o currículo escolar não se resume somente a documentos escritos e nem aos discursos de gestores, mas acima de tudo, devemos considerar que políticas

20 PELEGRINI; FUNARI, 2008, p. 89.

21 A palavra alteridade, que possui o prefixo alter, do latim, significa colocar-se no lugar do outro na relação interpessoal, com consideração, valorização, identificação, e dialogar com o outro, experienciando suas riquezas e limites. Na prática, alteridade se conecta aos relacionamentos tanto entre os indivíduos como entre grupos culturais religiosos, científicos e étnicos. $\mathrm{RECH}$, Vilma T. Pluralismo religioso: diálogo e alteridade no ensino religioso. Dissertação (Mestrado). Programa de Pós-Graduação em Teologia/PUCRS, Porto Alegre, $2009 . \quad$ Disponível em <http:/ / tede.pucrs.br/tde_busca/arquivo.php?codArquivo=2176>. Acesso em: 01 nov. 2011. 
educacionais e curriculares envolvem planejamentos vivenciados e reconstruídos no espaço escolar, que vão além da esfera governamental.

Mesmo sabendo que a organização curricular consiste num conjunto de atividades (distribuição de disciplinas/áreas de estudo, programas, métodos, procedimentos, técnicas, trabalho pedagógico, conhecimentos, ideias, hábitos, valores, convicções, recursos, artefatos, símbolos, etc.), desenvolvidas pela escola com a participação de todos, o currículo é resultado de negociações, durante processos conflituosos, devido à diversidade de ideias e concepções. ${ }^{22}$ Portanto, o nível de consciência dos discentes, depende muito da conscientização dos professores e demais funcionários da escola sobre a importância da diversidade cultural. Na leitura de Joelson Alves Onofre,

O currículo, pensado em toda a sua dinâmica, não se limita aos conhecimentos relacionados às vivências do educando, mas introduz sempre conhecimentos novos que, de certa forma, contribuem para a formação humana dos sujeitos. Nessa perspectiva, um currículo para a formação humana é aquele orientado para a inclusão de todos no acesso aos bens culturais e ao conhecimento. Assim, teremos um currículo a serviço da diversidade. ${ }^{23}$

$\mathrm{Na}$ perspectiva de Joelson Alves Onofre, portanto, permanecem práticas curriculares que perpetuam o saber hegemônico herdado. Observamos que é difícil romper com o saber do grupo dominante que possui estruturas para sua reprodução. Além disso, o currículo não se restringe a sistematizar informações, o que acarretaria uma postura vertical de repassar e reproduzir conteúdo. Assim sendo, é necessário questionar as compreensões hegemônicas de produção de conhecimento que perpassam a vida escolar.

Para atender e solucionar alguns problemas educacionais da disciplina de ER, em 1997, através do FONAPER, foram criados os Parâmetros Curriculares Nacionais para o Ensino Religioso (PCNER) que significou muito mais que um referencial curricular na medida em que determinou a própria constituição da identidade da disciplina escolar. Tornou-se o modelo para a disciplina "Ensino Religioso" na escola pública. ${ }^{24}$

Além dos PCN e PCNER, podemos ainda encontrar a Lei n. 10.639/2003, bem como diversos trabalhos publicados sobre a referida temática que se encontram disponíveis. Essa medida traz orientações de como a lei deve ser conduzida. A medida

22 SAVIANI, Nereide. Currículo: um grande desafio para o professor. Revista de Educação, São Paulo, n. 16, 2003. Disponível em: <http://renatosampaio63.com.br/documentos/sobrecurriculo42180.pdf>. Acesso em: 10 nov. 2012.

23 ONOFRE, Joelson A. Repensando a questão curricular: caminho para uma educação antirracista. Práxis Educacional, Vitória da Conquista, v. 4, n. 4, p. 104, jan./jun. 2008.

24 FÓRUM NACIONAL PERMANENTE DO ENSINO RELIGIOSO. Parâmetros Curriculares Nacionais para o Ensino Religioso (PCNER). São Paulo: Mundo Mirim, 2009. 
também faz parte do rol de ações afirmativas propostas pelo Governo Federal, como signatário de compromissos internacionais no combate ao racismo.

É pertinente ressaltarmos que o Currículo como Narrativa Étnico-Racial possibilita à escola repensar as narrativas hegemônicas que ao longo da história têm sido repassadas por meio de livros, lições, conteúdo curricular, datas festivas e comemorativas e outros, as quais contribuíram para formar uma sociedade elitista e preconceituosa.

Esta teoria de currículo centra sua análise na concepção de identidade, que não existe fora da história e do processo de representação. Sendo assim, "reconhecer o currículo como narrativa e reconhecer o currículo como constituído de múltiplas narrativas significa colocar a possibilidade de desconstruí-las como narrativas preferidas, como narrativas dominantes". 25

O negro pouco aparece na história do Brasil e as menções que são feitas, o são de forma negativa. A história apresentada é a história dos vencedores, dos dominadores. ${ }^{26}$ Por isso, Henrique Cunha Jr. enfatiza a importância de se falar de RMA na escola, pois,

[...] Falar nas religiões de base africanas na escola é relativo à história brasileira, onde as religiões de base africana foram parte importante da identidade dos africanos e afrodescendentes e através delas formação da resistência contra o escravismo criminoso e contra a dominação eurocêntrica. As religiões afrodescendentes são um marco da resistência dos povos africanos e descendentes no Brasil [...]. As religiões de matriz africana são parte integrante da consciência social processada por parte dos movimentos negros na atualidade [...]. Estas são parte do patrimônio cultural, material e imaterial, do povo brasileiro e desta forma estão inscritas na formação histórica que deve ser oferecida pela educação brasileira. ${ }^{27}$

Apesar de a escola brasileira ser um espaço multicultural, frequentada por diferentes grupos sociais e culturais, eles são invisíveis aos sistemas educacionais. Devemos, portanto, acima de tudo, revolucionar esse "conteúdo tradicional", que vem permanecendo, assim, intocado por várias gerações. Igualmente, problematizar a ideia de que existe uma humanidade universal, pois tal afirmação anula o princípio da diversidade cultural.

O currículo como narrativa étnico-racial constitui-se numa possibilidade de podermos contar a história silenciada, e de contribuir para a formação de novos cidadãos,

25 SILVA, Tomaz T. Alienígenas na sala de aula: uma introdução aos estudos culturais em educação. 3 . ed. Petrópolis: Vozes, 1995. p. 206.

26 SILVA FILHO, 2009.

27 CUNHA JR, Henrique. Candomblés: como abordar esta cultura na escola. Revista Espaço Acadêmico, n. 102, $2009 . \quad$ p. 20 98-99. Disponível em: <http://periodicos.uem.br/ojs/index.php/EspacoAcademico/article/viewFile/7738/481>. Acesso em: 16 nov. 2012. 
que compreendam que as diferenças não provocam em si as oportunidades desiguais. Histórias que, pela sua riqueza e detalhes, proporcionarão avançar na compreensão e no conhecimento de uma África desconhecida nos currículos escolares. ${ }^{28}$

O currículo escolar assume uma importância muito grande na diversidade cultural e principalmente na crítica da educação antirracista. Assim sendo, a diversidade cultural nacional e principalmente regional não pode ser ignorada na elaboração curricular de cada sistema de ensino. Essa questão é tão significativa que após a LDBEN de 1996 já ocorreram algumas emendas no texto original em relação aos currículos da educação básica. Um grande exemplo disso foi à obrigatoriedade do ensino sobre a história e a cultura afrobrasileira anunciada anteriormente.

Henry Giroux concebe o currículo como política cultural, e sustenta que ele não transmite apenas fatos e conhecimentos objetivos, mas também constrói significados e valores sociais e culturais. ${ }^{29}$ Logo, o currículo escolar é fundamental para a construção da identidade negra, pois no espaço escolar devemos desenvolver práticas pedagógicas que visem atender os anseios dos discentes. Nilma Lino Gomes afirma que a luta antirracista deve fazer compreender que a escola é a instituição responsável pelo "trato pedagógico da cultura" e, claro, do conhecimento. ${ }^{30}$

Sendo assim, discutir diversidade implica nos posicionarmos contra os processos de dominação. Os currículos e práticas escolares podem caminhar na direção de incorporar uma visão de educação que se aproxime do trato positivo da diversidade humana. De acordo com Nilma Lino Gomes, por diversas vezes, a diversidade aparece somente como um tema que transversaliza o currículo. ${ }^{31}$ Portanto, como a educação escolar pode se manter distante da discussão da diversidade se ela se faz presente no cotidiano escolar.

O FONAPER, 32 em justificativa do VI Congresso Nacional de ER (CONERE) realizado nas dependências do Centro Universitário La Salle (UNILASSALE) em Canoas/RS, nos dias 06 a 08 de outubro de 2011, em referência à educação brasileira no cenário nacional, expressou que:

[...] O currículo escolar é espaço marcado por tensões e disputas e, recentemente, de proposição de mudanças, principalmente após a promulgação da Resolução CNE/CEB n. 4/2010, que institui novas Diretrizes Curriculares Nacionais Gerais para a Educação Básica. Os

28 CUSTÓDIO, Rosalda I. O. A questão racial no âmbito das mudanças curriculares, propostas pela Lei 10.639/03: concepções, discursos e práticas. Dissertação (Mestrado) - Programa de Pós-Graduação em Desenvolvimento Regional, Universidade Federal do Amapá, Macapá: 2010. $133 f$ p. 77.

29 GIROUX, Henry. Pedagogia radical: subsídios. São Paulo: Autores Associados/Cortez, 1983.

30 GOMES, Nilma L. Educação cidadã, etnia e raça: o trato pedagógico da Diversidade. In: CAVALLEIRO, Eliane. (Org.). Racismo e antirracismo na educação: repensando nossa escola. São Paulo: Selo Negro, 2001.

31 GOMES, 2008.

32 Ver notícia completa disponível em: <http://www.fonaper.com.br/noticia.php?id=1180>. 
currículos das escolas públicas brasileiras são constantemente desafiados a acolher, conhecer e respeitar a diversidade de sujeitos presentes no cotidiano escolar. Diferentes representações sobre o Outro são veiculadas, (re) produzidas e (res) significadas nas/pelas relações sociais e práticas curriculares dentro da escola, influenciando comportamentos e atitudes que podem legitimar processos de exclusão e desigualdade existentes nos contextos micro e macros sociais. É na perspectiva da formação plena do cidadão, no contexto de uma sociedade cultural e religiosamente diversa, na qual todas as crenças, expressões religiosas e não religiosas devem ser respeitadas, que se insere o Ensino Religioso como componente curricular nas escolas públicas. ${ }^{33}$

Com isso, percebemos que o debate sobre o currículo escolar é uma necessidade permanente, principalmente na atualidade, devido aos grandes problemas que a sociedade vem enfrentando com relação à discriminação e a intolerância religiosa no espaço escolar. Embora o currículo seja um elemento de suma importância dentro da teoria da educação, verificamos que ele vem sendo encarado como um elemento de pouca relevância quando se trata, por exemplo, da implementação de ações afirmativas de inclusão das RMA no currículo da disciplina de ER.

Diante dessa perspectiva, é pertinente observarmos que o currículo escolar reflete experiências em termos de conhecimentos que serão válidas ao discente não somente no ensino em questão, mas, sobretudo, em todo o processo de formação como cidadão, pois o currículo das escolas hoje está baseado na cultura dominante, expressando-se na linguagem dominante e sendo transmitido através do código cultural da dominação, funcionando como mecanismo "natural" de exclusão dos dominados, que, por não verem sua cultura reconhecida, conformam-se com seu fracasso escolar e com a condição de dominados. ${ }^{34}$

Sobre ainda a questão curricular, o Museu Afro-Brasileiro (MAFRO), ${ }^{35}$ através do Projeto de Atuação Pedagógica e Capacitação de Jovens Monitores sobre religiosidade afro-brasileira, entende que:

O desafio de aplicar a Lei 10.639/03 constitui-se, assim, não apenas em incorporar novos conteúdos ao currículo, mas em avaliar como o próprio currículo foi estruturado, a quais interesses corresponde e em que valores civilizatórios é pautado. Esta lei traz a possibilidade de repensar o currículo não só como o que se aprende, mas como se aprende, para quê e para quem é destinada a educação escolar. Desta maneira, torna-se possível pluralizar

33 FÓRUM NACIONAL PERMANENTE DO ENSINO RELIGIOSO (FONAPER). VI Congresso Nacional de Ensino Religioso (CONERE) realizado nas dependências do Centro Universitário La Salle (UNILASSALE) em Canoas/RS, nos dias 06 a 08 de outubro de 2011. Disponível em: <http://www.fonaper.com.br/noticia.php?id=1180>. Acesso em: 15 maio 2012.

34 SILVA, Tomaz T. Documentos de identidade: uma introdução às teorias do currículo. Belo Horizonte: Autêntica, 2003. p. 14.

35 Para maiores informações, ver material complete no site do Museu Afro-Brasileiro (MAFRO). 
a educação, adequando-a a sujeitos heterogêneos, levando em conta as diferenças culturais, étnico-raciais, religiosas, de gênero e sexualidade, entre outras, existentes entre eles. ${ }^{36}$

Verificamos que a diversidade cultural religiosa prevista na disciplina de ER, como política pública de Estado e de Governo, em que se insere o texto disposto na Lei de Diretrizes e Bases da Educação Nacional (LDBEN), especialmente, em relação ao ensino da Cultura e História da África e dos Afro-Brasileiros, previstos no Art. 26-A, é de caráter obrigatório e permanente, além da necessidade de manifestação dos diversos segmentos religiosos brasileiros.

A escola no seu currículo "oficial" indica uma educação democrática, crítica e participativa. Um discurso de democracia e de pluralidade que se amplia e se sofistica. Os PCN são um exemplo claro disso, ao enfatizarem o tema transversal pluralidade cultural como forma de superação da discriminação racial. No entanto, na experiência vivenciada pelos sujeitos, no cotidiano escolar, apresentam muito mais processos de manutenção sutil do racismo do que práticas que caminhem na direção de sua ultrapassagem. ${ }^{37}$

Observamos que os Temas Transversais expressam a vontade do poder público de atender genericamente reivindicações históricas dos movimentos negros. Porém, ao diluir os conteúdos em diversas áreas do conhecimento e não definir objetivamente os momentos em que a questão étnico-racial deverá ser incorporada à prática docente, parecem não evitar omissões e silenciamentos. Por isso, os conteúdos afro-brasileiros e africanos continuarão sendo reivindicados na educação básica. Eugénia da Luz Silva Foster acredita que,

[...] Os PCN, ao trazem para o âmbito curricular a questão da diversidade e da pluralidade, constituem um ponto de partida para fragilizar as tendências homogeneizadoras que têm imperado na educação nacional, configurando-se como uma das tentativas de estremecer o consenso de uma identidade nacional homogênea, não obstante, nossas discordâncias com relação à natureza da política à qual eles estão atrelados, e à superficialidade com que instigam a pensar certas questões. ${ }^{38}$

Nos currículos escolares, verificamos claramente que a cultura europeia tem sido valorizada em detrimento da cultura do negro, apesar deste se constituir em maioria do

36 MUSEU AFRO-BRASILEIRO (MAFRO). Centro de Estudos Afro-Orientais da Universidade Federal da Bahia. Setor religiosidade afro-brasileira. Projeto de Atuação Pedagógica e Capacitação de Jovens Monitores. Material do professor. Ano 2006, p. 5. Disponível em: <http://www.mafro.ceao.ufba.br/userfiles/files/Material\%20do\%20Professor\%20-\%20AfroBrasileiro.pdf $>$. Acesso em: 18 jul. 2012.

37 FOSTER, Eugénia L. S. Racismo e movimentos instituintes na escola. Tese (Doutorado) - Faculdade de Educação, Universidade Federal de Fluminense, Rio de Janeiro, 2004. 398f. Disponível em <http://www.bdtd.ndc.uff.br/tdearquivos/2/TDE-2005-03-15T14:39:57Z70/Publico/Parte\%201-TeseEugenia\%20Foster.pdf>. Acesso em: 29 out. 2011.

38 FOSTER, 2004, p. 10. 
povo brasileiro. Esse ensino formal, de base branca europeizada, mostra-nos uma imagem que inferioriza o negro brasileiro. Apresenta modelos de negros com estereótipos negativos e através dessa imagem é imposto a esses alunos negros um ideal de ego branco, contribuindo dessa maneira para baixar sua autoestima.

Quando analisamos de maneira atenta os conteúdos que são desenvolvidos de forma explícita na maioria das instituições escolares e aquilo que é enfatizado nas propostas curriculares, chama-nos fortemente a atenção a arrasadora presença das culturas que podemos chamar de hegemônicas.

É tarefa importante o favorecimento da percepção da riqueza e do valor de um mundo plural e diversificado. As religiões não são apenas genuinamente diferentes, mas também autenticamente preciosas. A diversidade cultural e religiosa deve ser reconhecida com traço de riqueza e valor, um valor que é irredutível e irrevogável. O momento atual exige, porém, uma outra perspectiva e sensibilidade. Não há mais espaço no tempo do pluralismo religioso para narrativas absolutizadoras e para linguagens desclassificadoras.

\section{Considerações finais}

Uma grande conquista para educação brasileira foi a Lei n. 10.639/2003, enfatizada anteriormente. Tal lei, de certa forma, abriu mais espaço para a discussão sobre a discriminação racial e incentivou o maior contato com a riqueza da cultura africana e afro-brasileira. No entanto, são vários os desafios no que tange às políticas educacionais de inclusão de conteúdos referentes à História da África e/ou Cultura Afro-Brasileira, na educação escolar no Amapá. Acreditamos que sem a valorização e o respeito às RMA na disciplina de ER e no Ensino da Cultura e História da África e dos Afro-Brasileiros não prevalecerá o dispositivo legal na preservação e valorização da cultura.

A promulgação da Lei n. 10.639/2003 representou uma importante conquista do movimento negro, dos movimentos sociais e também de parte de intelectuais brasileiros, porém precisamos deixar claro, que o objetivo da lei não é apenas estimular o conhecimento acerca da história dos afrodescendentes, mas principalmente ajudar a eliminar o racismo ainda presente na sociedade brasileira.

O Brasil é um país rico na sua diversidade cultural e religiosa. Sabemos que é responsabilidade do Estado à elaboração de diretrizes para definição de uma política pública voltada para a educação, na perspectiva da diversidade, assim como, uma política educacional voltada para a proteção das RMA como patrimônio cultural.

No atual contexto educacional, a diversidade nos desafia a repensar, reorganizar e reestruturar a educação para as relações étnico-raciais e educação em direitos humanos. Os estados brasileiros se constituem em meio à riqueza da diversidade. Porém, no Amapá, assim como nos demais estados do Brasil, percebemos a existência de situações preconceituosas, além de processos discriminatórios de desigualdades, contradições, 
autoritarismos, dentre outros, os quais são produzidos e reproduzidos nos diferentes espaços educativos.

Sabemos que a tarefa de implementar a Lei n. 10.639/2003 nas escolas de educação básica é difícil e complexa devido aos entraves que a sociedade vem enfrentado no processo de reconhecimento de sua identidade cultural. É exatamente diante dessa realidade escolar adversa que reforçamos a importância da referida lei para a educação brasileira. Verificamos na literatura contemporânea que as RMA encontram-se instaladas no espaço brasileiro, apresentando-se como religiões estruturalmente organizadas, com crenças e ritos, portanto, possuidoras de fenômenos religiosos.

Ao tratarmos das RMA na educação escolar no Amapá, precisamos implementar novos olhares sobre a nossa prática pedagógica, propiciando a construção da identidade do aluno e um espaço escolar capaz de lidar com as diferenças na qual se insere a escola e sua comunidade.

Assim, acreditamos que uma releitura das políticas educacionais excludentes da cultura africana no processo escolar e na formação de docentes capacitados para reconhecer as identidades dentro das diferenças culturais seja pertinente. Mesmo porque a diversidade cultural como patrimônio constitui um direito fundamental de toda a humanidade, pois se trata de uma série de manifestações que congrega variadas formas de saber, fazer e criar.

\section{Referências:}

BRASIL. Constituição Federal. Brasília, 1988. Disponível em: <http://www.senado.gov.br/sf/legislacao/const/con1988/CON1988_30.06.2004/CON1 988.pdf>. Acesso em: 28 ago. 2011.

. Lei n. 10.639, de 09 de janeiro de 2003: instituiu a obrigatoriedade do ensino de História e Cultura Afro-Brasileira e Africana no Currículo da Educação Básica. Disponível em: <http:/ / www.planalto.gov.br/ccivil03/Leis/2003/L10.639.htm>. Acesso em: 01 out. 2011.

. Ministério da Educação. Parâmetros Curriculares Nacionais: pluralidade cultural e orientação sexual. Brasília: SEF/ MEC, 1998b.

CONFERÊNCIA NACIONAL DE PROMOÇÃO DA IGUALDADE RACIAL. Estado e sociedade promovendo a igualdade racial (CONAPIR): relatório final. Brasília: Secretaria Especial de Política de Promoção da Igualdade Racial/Conselho Nacional de Promoção da Igualdade Racial, 2005. Disponível em:

<www.planalto.gov.br/seppir/publicacoes/relatorio_final_conapir.pdf>. Acesso em: 14 jan. 2012.

CUNHA JR, Henrique. Candomblés: como abordar esta cultura na escola. Revista Espaço Acadêmico, n. 102, nov. 2009. Disponível em: 
<http://periodicos.uem.br/ojs/index.php/EspacoAcademico/article/viewFile/7738/481 >. Acesso em: 16 nov. 2012.

CUSTÓDIO, Elivaldo S. Políticas públicas e direito ambiental cultural: as religiões de matrizes africanas no currículo escolar no Amapá. Dissertação (Mestrado em Direito Ambiental e Políticas Públicas) - Universidade Federal do Amapá, Macapá, 2014. $198 f$.

CUSTÓDIO, Rosalda I. O. A questão racial no âmbito das mudanças curriculares, propostas pela Lei 10.639/03: concepções, discursos e práticas. Dissertação (Mestrado) - Programa de PósGraduação em Desenvolvimento Regional, Universidade Federal do Amapá, Macapá: 2010. 133f.

ELIADE, Mircea. O sagrado e o profano: a essência das religiões. São Paulo: Martins Fontes, 2001.

FIORILLO, Celso A. P. Curso de direito ambiental brasileiro. 13. ed. rev. atual. e ampl. São Paulo: Saraiva, 2012.

FÓRUM NACIONAL PERMANENTE DO ENSINO RELIGIOSO (FONAPER). VI Congresso Nacional de Ensino Religioso (CONERE) realizado nas dependências do Centro Universitário La Salle (UNILASSALE) em Canoas/RS, nos dias 06 a 08 de outubro de 2011. Disponível em: <http://www.fonaper.com.br/noticia.php?id=1180>. Acesso em: 15 maio 2012.

Mundo Mirim, 2009.

. Parâmetros Curriculares Nacionais para o Ensino Religioso (PCNER). São Paulo:

FOSTER, Eugénia L. S. Racismo e movimentos instituintes na escola. Tese (Doutorado) Faculdade de Educação, Universidade Federal de Fluminense, Rio de Janeiro, 2004. 398f. Disponível em <http:/ / www.bdtd.ndc.uff.br/tdearquivos/2/TDE-2005-03-

15T14:39:57Z70/Publico/Parte\%201-Tese-Eugenia\%20Foster.pdf>. Acesso em: 29 out. 2011.

GIROUX, Henry. Pedagogia radical: subsídios. São Paulo: Autores Associados/Cortez, 1983.

GOMES, Nilma L. Educação cidadã, etnia e raça: o trato pedagógico da Diversidade. In: CAVALLEIRO, Eliane. (Org.). Racismo e antirracismo na educação: repensando nossa escola. São Paulo: Selo Negro, 2001.

. Indagações sobre currículo: diversidade e currículo. Brasília: Ministério da Educação, Secretaria de Educação Básica, 2008.

INSTITUTO BRASILEIRO DE GEOGRAFIA E ESTATÍSTICA (IBGE). Censo Demográfico 2010. Disponível em:

<ftp:/ /ftp.ibge.gov.br/Censos/Censo_Demografico_2010/Caracteristicas_Gerais_Religia o_Deficiencia/tab1_4.pdf>. Acesso em: Acesso em: 30 jun. 2012.

MUSEU AFRO-BRASILEIRO (MAFRO). Centro de Estudos Afro-Orientais da Universidade Federal da Bahia. Setor religiosidade afro-brasileira. Projeto de Atuação Pedagógica e Capacitação de Jovens Monitores. Material do professor. Ano 2006. Disponível 
em: <http:/ / www.mafro.ceao.ufba.br/userfiles/files/Material\%20do\%20Professor\%20\%20Afro-Brasileiro.pdf>. Acesso em: 18 jul. 2012.

ONOFRE, Joelson A. Repensando a questão curricular: caminho para uma educação antirracista. Práxis Educacional, Vitória da Conquista, v. 4, n. 4, p. 104, jan./jun. 2008.

ORGANIZAÇÃO DAS NAÇÕES UNIDAS PARA A EDUCAÇÃO, A CIÊNCIA E A CULTURA (UNESCO). Convenção relativa à luta contra a discriminação no campo do ensino. Paris: UNESCO, 2003.

PELEGRINI, Sandra de C. A.; FUNARI, Pedro P. A. O que é patrimônio cultural imaterial. São Paulo: Brasiliense, 2008.

PEREZ, Léa F. Breves notas e reflexões sobre a religiosidade brasileira. Edição Especial, Brasil 500 anos, junho de 2000. Belo Horizonte: Imprensa Oficial dos Poderes do Estado, 2000. Disponível em: <http://antropologia.org.br/arti/colab/a8-lfreitas.pdf>. Acesso em: 15 nov. 2011.

PRANDI, Reginaldo. As religiões negras do Brasil: para uma sociologia dos cultos afrobrasileiros. Revista USP, São Paulo, v. 28, p. 64-83, dez./fev. 1995/1996. Disponível em: <http://www.usp.br/revistausp/28/05-prandi.pdf>. Acesso em: 18 jul. 2012.

RECH, Vilma T. Pluralismo religioso: diálogo e alteridade no ensino religioso. Dissertação (Mestrado). Programa de Pós-Graduação em Teologia/PUCRS, Porto Alegre, 2009.

Disponível em <http://tede.pucrs.br/tde_busca/arquivo.php?codArquivo=2176>. Acesso em: 01 nov. 2011.

RODRIGUES, José E. R. Patrimônio cultural: aspectos polêmicos. Revista de Direito Ambiental, São Paulo, ano 6, n. 21, jan./mar. 2001.

SAVIANI, Nereide. Currículo: um grande desafio para o professor. Revista de Educação, São Paulo, n. 16, 2003. Disponível em:

<http://renatosampaio63.com.br/documentos/sobrecurriculo42180.pdf>. Acesso em: 10 nov. 2012.

SILVA FILHO, José B. da. Apontamentos sobre a história do negro no Brasil. Cuiabá, EDUFMT, 2009.

SILVA, Kalina V.; SILVA, Maciel H. Dicionário de conceitos históricos. 2. ed. São Paulo: Contexto, 2006.

SILVA, Tomaz T. Alienígenas na sala de aula: uma introdução aos estudos culturais em educação. 3. ed. Petrópolis: Vozes, 1995.

. Documentos de identidade: uma introdução às teorias do currículo. Belo Horizonte: Autêntica, 2003.

WOLFF, Elias. Humanismo e Religião. In: WOLFF, Elias; BENTO, Fábio Régio. Cristiatnismo, humanismo e democracia. São Paulo: Paulus, 2005. 